\title{
Large Scale Solar Thermal Systems for the Solution of Europe`S Expansion Of Energy Demand
}

\author{
Erdogan Guk ${ }^{1, *}$ and Naci Kalkan ${ }^{2}$ \\ ${ }^{1}$ University of Southampton, School of Engineering Sciences, Sustainable Energy Technologies, \\ University Road, Southampton SO17 1BJ, UK \\ ${ }^{2}$ Bitlis Eren University, Faculty of Mechanical Engineering, Energy Institute, Bitlis 13000,Turkey
}

Received 1 April 2014; Accepted 14 April 2014

\begin{abstract}
This paper describes solar thermal technologies for the solution of long term Europe`s energy problem with better reliability. A short overview about solar energy is explained with a basic energy analysis. This report also includes some evaluations and discussions of solar energy systems in the following pages. The general purpose of the article is to understand how efficiently solar thermal systems generates energy, and solve the Europe's increasing energy demand in our century.
\end{abstract}

Keywords: Solar thermal technologies, solar energy, Europe energy demand, energy production from solar systems, energy planning.

\section{Introduction}

With the industrial revolution, some countries such as the USA and some EU countries focused on getting high level of technology. Therefore, these countries strongly desired to utilize more energy mainly electricity to meet required energy demand (Wichert, 1997). This situation caused a growth of some natural's disaster such as climate changes and air pollution due to using fossil fuels as main energy sources. Thus, European countries decided to apply viable alternative energy suppliers which are sustainable and affordable (Summerer et al., 2003). Furthermore, The Commission will offer aspiring targets for $\mathrm{CO} 2$ emission cuts, with the objective of limiting global climate change. Sharing of renewable energy sources in the overall energy mix will be considered as an important point and it will be also restated to improve the EU's energy efficiency by $20 \%$. By making these decisions it is estimated that Europe will be the most energy efficient region in the world in terms of sustainability, competitiveness and security of supply (Barrosa, 2005).

Regarding these perspectives, thermal solar system is pointed out as the most applicable option by European countries since $50 \%$ of European total energy is being used for heating and cooling (ESTTP, 2006) and the system has a perfect capacity, which rose from $10 \mathrm{GW}$ th in 2005 to $200 \mathrm{GW}$ th by 2030 , and soon became an option on the world electricity market. Besides, when it is supported by the new technology, it leads to further cost reduction $(50 \%)$ in the electricity cost (Trieb, 2000). There were some important attempts in European countries to achieve this aim such as CEN/TC312 which was created to deal with solar thermal collectors as a renewable solution for increasing energy demand. This committee mainly centered on the efficiency of this system for EU and the working process of the systems considering the EU standards. Moreover, many different working groups were created, existing standards were compared with international standards (ISO) and as a result of these studies some significant parameters are pointed out about the solar thermal system which are reliability, durability and safety (Kotsaki, 2001).

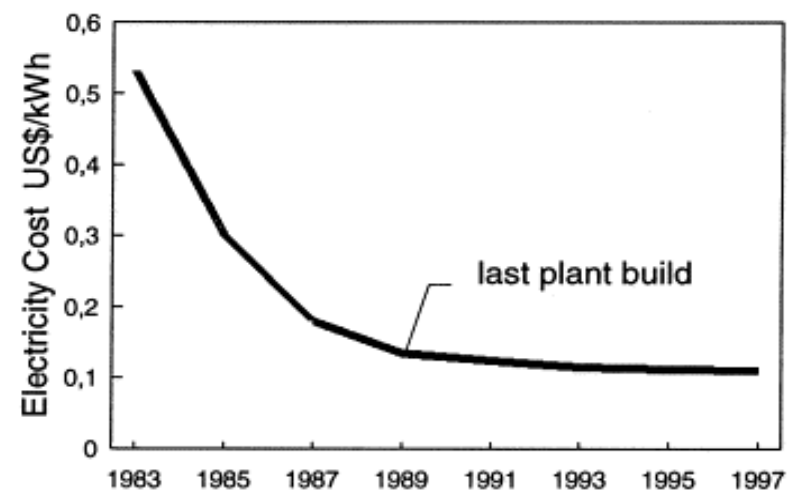

Fig 1. Learning curve of solar power plants (adapted from: Trieb, 2000)

\section{Advantages}

- Free resources

- Acceptable technology

- Acceptable profit

- Acceptable risk (Trieb, 2000)

- Zero CO2 emission 


\section{Disadvantages}

- A big amount of radiation are diffused by the earth

- The position of shine changes continuously

- Sunshine is extremely affected by the seasonal diversity

- The energy from the sun can not directly stored Requirements

- New vision for applying solar thermal system and conducting a strategic research agenda

- Accelerating the technological development of solar thermal system

- For operation of the system, recommending industry, researches investors and politicians (ESTTP, 2006).

\section{The Principles of the Solar Thermal System}

Basically, in the solar thermal system, the sun is used as a main energy sources and the sunlight are captured by a panel to transform it into heat thereafter the heat is used to generate electricity by applying an engine cycle (Lovegrove et al., 2006). A considerable amount of electricity is generated by using thermally driven steam-based system. There are many kinds of collectors and receivers to obtain solar radiation effectively such as flat plates, metal tubes or glass cylinders and tubular, volumetric and heat pipe respectively (Lovegrove et al., 2006). Additionally, with the high development in conversation system (rankine cycle, stirling engine, brayton cycle and others), it is possible to increase the efficiency of solar thermal system.

\section{Capacity of the System}

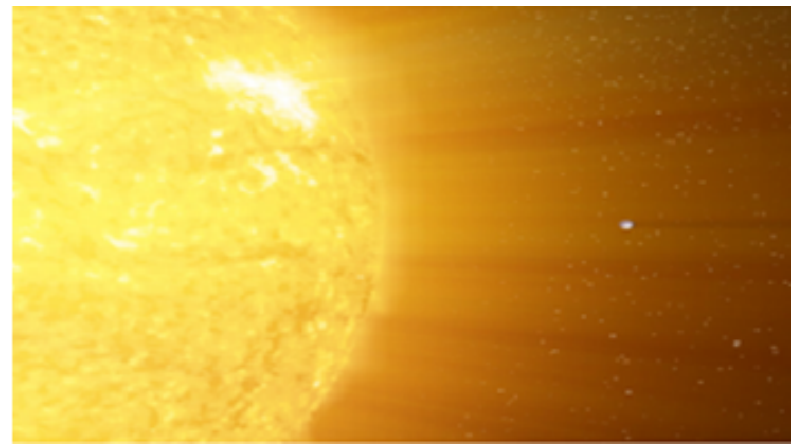

Fig. 2-.Relative size of the Earth compared to the Sun (NASA)

It is crucially important to have large scale solar thermal system (fig.2) in European countries and it is considered to be affordable with today's high developed technology since there are many efficient engines including gas turbine, stirling and steam engine which can be really efficient $(30 \%$ $40 \%$ ) and are capable to generate $10-100 \mathrm{MW}$ power(solar thermal industry report). For instance, a German company (Schaech Bergermann and Partner) constructed a solar dish stirling system in southern Spain and 30,000MWh electricity is generated between 1996 and 2000 by this system. Furthermore, Argiriou and Mirasgedis (2003) also mentioned that there is a great increase in receiving large scale of solar thermal systems. Also, it is proved that the solar thermal market will be the most preferable application as a consequence of the high increasing intensity in oil and natural gas prices, which are thought major energy resources for European countries, and the rise in the capacity of solar thermal system. For example, there was a substantial growth in the capacity of solar thermal used energy in Greece in domestic needs between 1998 and 2000 (from 1\% to 99\%), (Argiriou and Mirasgedis, 2003). It is clearly seen from the data that the solar power thermal application will be the most preferable method to generate electricity and provide hot water for household needs and for industrials requirements.

\section{Future Expectations}

Although fossil fuels as an energy source have many negative impacts on people life, it is considered that the supremacy of these sources will not drop severely within the next 20 to 30 years (Summerer et al., 2003). On the other hand, there were some considerable studies which conducted by Sebolt et al., (2001), to deliver $513 \mathrm{GWe}$ power, which are equal to the consumption of Europe in 2020, by designing a full deployed solar thermal system. To figure out the effect of solar thermal system on Europe electricity needs in 2020, the solar radiation rate is calculated and as it can be clearly seen from the fig. 3 . the load levels amount to $330 \mathrm{GWe}$ for January and $280 \mathrm{GWe}$ for July. All these data show that solar thermal system will cover $15 \%$ of European total electricity needs in 2020 .

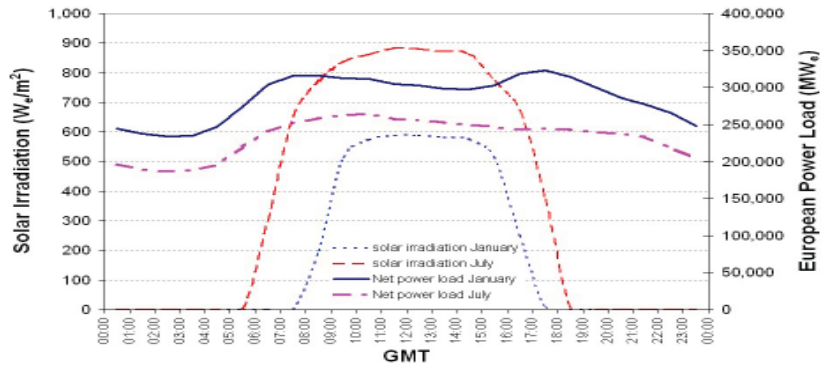

Fig 3. Typical winter and summer day solar irradiation and European electricity load profiles (adapted from: Sebolt et al., 2001).

In addition, Mills (2004) also agree with the point that solar thermal will be more applicable in the near future and he mentioned that solar thermal rates will exceed $20 \%$ per annum for the next 30 years and it will be a dominant market in the generation of electricity by 2050 .

\section{Conclusion}

Solar thermal system has a great capacity on the verge of competitiveness and this market will produce large scale of energy especially electricity in the long term energy programs in the very near future (Trieb, 2000). It is clear to understand that this new applicable method strongly depends on the support from government or private companies. Even though there is a huge concern about the efficiency of this method for European countries, new investors should be informed about the efficiency of this method by designing effective and more efficient frames and explaining the possible risks or payback processes due to the vital importance of applying these kinds of renewable applications. When this aims are achieved, it is so clear to have large scale of solar thermal system in a short time. 


\section{References}

[1] Argiriou, A.A. \& Mirasgedis, S., 2003. The solar thermal market in Greece - Review and perspectives. Renewable and Sustainable Energy Reviews, 7(5), p.397-418. Available at: $\mathrm{http}: / /$ www.scopus.com/inward/record.url?eid=2-s2.00042090434\&partnerID $=40 \& m d 5=05 \mathrm{~d} 575$ f8a $7 \mathrm{ec} 7 \mathrm{fle} 0 \mathrm{a} 4 \mathrm{~d} 6086551$ efe 26 .

[2] Costella, T., 2010. Solar thermal energy available at: http://www.solarthermalworld.org/content/solar-thermal-energyindustry-report-2008-0. [Accessed date: 10-11-2012]

[3] Costella, T., 2010. Solar thermal vision 2030 available at: http://www.solarthermalworld.org/content/solar-thermal-vision2030-2006. [Accessed date: 08-11-2012]

[4] European Commission, 2005. Working together for growth and jobs. A new start for the Lisbon Strategy. Available at: http://europa.eu.int/growthandjobs/pdf/COM2005_024_en.pdf. [Accessed date: 11-10-2012]

[5] Kotsaki, E., 2001. European solar standards, Final approval of CENV/TC312. Focus .2(5).p.40-41. Available at:http://www.sciencedirect.com/science/article/pii/S147108460180 0779. [Accessed date: 06-11-2012]

[6] Lovegrove, K., Luzzi, A. and Kreetz, H., 1999. A solar driven ammonia based thermochemical energy storage system. Solar Energy, 67(4-6), 309-316.
[7] Mills, D., 2004. Advances in solar thermal electricity technology. Solar Energy, 76(1-3), p.19-31. Available at: http://linkinghub.elsevier.com/retrieve/pii/S0038092X03001026. [Accessed date: 03-11-2012]

[8] Seboldt, W. et al., 2001. European Sail Tower SPS Concept. Acta Astronautica. 48(5-12), p.785-792. Available at: http://www.sciencedirect.com/science/article/B6V1N-45TM3R1$1 \mathrm{~V} / 2 / \mathrm{fe} 3 \mathrm{~b} 3 \mathrm{~b} 86713 \mathrm{fbf} 4 \mathrm{ae} 2892166341648 \mathrm{ce}$. [Accessed date: 05-112012]

[9] Summerer, L., Vasile, M. \& Biesbroek, R., 2003. Available at http://www.esa.int/gsp/ACT/doc/POW/ACT-RPR-NRG-2003-IACSpaceTerrestrialSolarPlantsEuropeanPrespectives.pdf. [Accessed date: 11-10-2012]

[10]Trieb, F., 2000. Competitive solar thermal power stations until 2010-the challenge of market introduction. Renewable Energy, 19, p.163-171.

[11] Wichert, B., 1997. PV-diesel hybrid energy systems for remote area power generation. A review of current practice and future developments. Renewable and Sustainable Energy Reviews: 1(3), p.209-228. Available http://linkinghub.elsevier.com/retrieve/pii/S1364032197000063 